\title{
Heidegger, técnica e educação: uma meditação histórico-ontológica
}

Marcos Aurélio Fernandes

Universidade de Brasília

\section{Resumo}

Este artigo, seguindo as indicações do pensamento meditativo de Heidegger, questiona o sentido histórico ontológico da técnica, investigando seus fundamentos metafísicos. Depois de sondar a história do ser do ente na antiguidade grega e na romanidade, investiga a verdade do ente na modernidade, em que a educação é vista na ótica da funcionalidade e do sistema e ócio se subordina ao negócio. A técnica é o fim da era metafísica, não só no sentido de término, mas também de plenitude de realização e transformação, que acena para outro princípio do pensar no porvir e, por conseguinte, um outro modo do homem habitar a terra e uma outra configuração essencial da educação.

Palavras-chave: Heidegger; técnica; educação.

\section{Resumen}

Este artículo, siguiendo las indicaciones del pensamiento meditativo de Heidegger, pregunta por el sentido histórico ontológico de la técnica, haciendo la investigación de sus fundamentos metafísicos. Después de sondear la historia del ser de los seres en la antigua Grecia y en la romanidad, investiga la verdad de los seres en la modernidad, donde la educación es vista desde la perspectiva de la funcionalidad y del sistema y el ocio está subordinado al negocio. La técnica es el fin de la metafísica, no sólo como término, sino también como plenitud de realización y transformación, señala otro principio del pensar futuro y, por lo tanto, otra forma del hombre habitar en la tierra y otra configuración esencial de la educación.

Palabras-clave: Heidegger; técnica; educación. 


\section{História e Metafísica}

$\int\left[\begin{array}{l}\text { eidegger pensa a questão da essência da técnica em seu caráter } \\ \text { histórico-ontológico. Ele medita sobre o seu sentido a partir da } \\ \text { determinação metafísica da história ocidental, refletindo sobre }\end{array}\right.$ suas destinações, suas peripécias, vicissitudes e percalços. Neste pensar, a história da humanidade ocidental deixa de ser considerada apenas em sua concreção ôntica e passa a ser também considerada em seu concrescer ontológico. Ela deixa de ser considerada apenas como a dimensão dos fatos e feitos humanos e de suas condições fatuais, e passa a ser tomada também como o horizonte da facticidade do acontecer dos mundos humanos, de suas decisões e encaminhamentos. Ela deixa de ser tematizada apenas e tão somente como algo que diz respeito ao homem enquanto simples ente entre outros entes e passa a ser tematizada como o que concerne ao homem, desde o fundo da sua humanidade, como o ente ao qual, em diferentes épocas com suas configurações típicas, se confia os modos de aparecer da entidade do ente como tal e no seu todo, ou seja, as figuras típicas de sua verdade.

É que, desde o fundo de sua humanidade, o homem se configura sempre de novo de modo epocal, num diálogo e confronto com a realidade do real e com suas realizações. Por isso, em cada época, cada vez de novo e de modo novo, o homem procura explicar-se com a verdade do ente como tal e no seu todo, isto é, com o modo como o ser, no sentido da entidade do ente, se dá e se revela, à medida que também se subtrai e se vela. É a partir da estruturação fundamental da conjunção de homem e verdade do ente, que se esboça a posição metafísica de fundo de uma época. Esta posição metafísica de fundo predelineia o horizonte da experiência humana de uma época e é a partir dela que o homem se comporta com o ente que ele é e com o ente que ele não é, com o ser em sua verdade, em seu sentir e pensar, em suas ações e omissões. Desde esta posição metafísica de fundo esboça-se o quadro epocal em que se desenham as tendências dos modos de crer e saber, criar, pensar e agir, trabalhar e festejar, lutar e dominar, amar e morrer. Esta 
posição metafísica de fundo se articula de modo quádruplo: pelo modo como se projeta o ser do ente, ou seja, sua entidade; pelo modo como se delimita a essência da verdade do ente; pelo modo como o homem é homem e se sabe a si mesmo no relacionamento de ser e pensar com o ser do ente no seu todo; e, enfim, pelo modo como o homem, no exercício de sua responsabilidade de ser, recebe e dá a medida à verdade do ente enquanto tal e no seu todo (cf. Heidegger, 1998b, p. 120).

A história do ocidente é essencialmente filosófica. Filosofia é, desde Platão, metafísica. A técnica é o fim da história da metafísica (cf. Heidegger 1988, p. 61-62; 1999, p. 95-96). Fim não significa, aqui, o mero cessar, do extinguir-se, do não mais ser presente, do desaparecer de uma vigência. Nem significa a decadência, a incapacidade de perdurar, o não mais ir adiante. Fim significa, ao contrário, plenitude de uma realização. Fim tem também, aqui, um sentido tópico, uma significação de lugar. Neste sentido, o fim é ali onde o todo de uma história se recolhe em sua mais extrema possibilidade. Fim é, pois, recolhimento. O fim é o princípio na plenitude de sua realização. Nas palavras do fim se escutam o princípio das transformações. Por isso, o fim impõe a necessidade do diálogo pensante com o princípio de uma história. Ao mesmo tempo, no fim, o pensamento entra em rito de passagem e pressente o apelo de outro princípio. Assim, no fim da filosofia enquanto metafísica, se anuncia o porvir de um outro princípio do pensar. Mas, este outro princípio só pode ser acolhido num diálogo de ausculta com o primeiro princípio e com seus desdobramentos históricos.

Metafísica é o pensamento que pensa o ente no todo, em sua amplidão, em sua profundidade, em sua originariedade (cf. Heidegger, 1987a, p. 2-5; 1987b, p. 34-37). A este todo pertence, cada vez de modo diverso, o mundo, o homem, Deus. Metafísica é o pensamento que pensa o ente tendo em vista o ser. Isso quer dizer: este pensar pressupõe o comum pertencer e o referir mútuo de ente e ser. A atuação deste pensar acontece 
como um representar fundamentador, ou seja, como um representar que procura apresentar todo o ente desde o seu fundamento. O ser é tomado desde o princípio como fundamento do ente. Fundamento significa a partir donde o ente, passível de conhecimento, de ação e de trabalho, é o que é e como é, em seu devir, em seu passar e permanecer (Heidegger, 1988, p. 61$62 ; 1999$, p. 95).

\section{Os fundamentos metafísicos da técnica moderna}

O ser é o fundamento que, a cada vez, traz à luz o ente em seu respectivo viger, em seu respectivo estar presente e vigorar (Anwesen). Para dizer este ser trazido, que tem o caráter de vir e chegar à presença, à vigência (Anwesenheit), os gregos usavam o nome $\pi \alpha \rho \circ v \sigma ı \varpi \alpha$ (parousía) (cf. nota de Franco Volpi, em Heidegger, 1995, p. 986) ${ }^{1}$. Já para dizer o caráter de ser

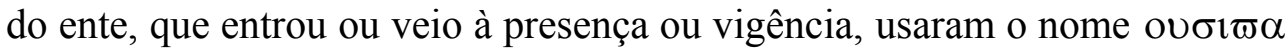
(ousía) (cf. Aristóteles, Categorias, V, 2 a 11-19; Heidegger, 1998b, p. 369370). $\mathrm{Na}$ era da metafísica, a entidade do ente, ou seja, a presença do presente, a vigência do vigente, se determina de diversos modos em diversas épocas, dependendo de como se compreende e se interpreta a presença do presente em seu sentido mais próprio, originário e fundamental, ou seja, em seu perdurar constante, permanente, como tal. Assim, a entidade do ente foi determinada, em Platão, partindo do aparecer e da luz, como $1 \delta \varepsilon \varpi \alpha ~(i d e ́ a)-$ a doação do ser como aspecto, forma originária, perfilagem, tipo, e esta,


(tò kathólou), o universal (Heidegger, 1998b, p. 72). Desde Platão, a tensão criadora de identidade e diferença que conjugava ser e devir, ser e aparecer, ser e não-ser, perde vigor e cadência, e, em seu lugar, entra o $\chi \omega \rho ı \sigma \mu о \varpi \sigma$, a

\footnotetext{
${ }^{1}$ A língua latina usa o verbo "adesse": estar perto, estar presente, estar entre ou junto de; alguns usos do verbo, em se tratando de comportamento humano, trazem o significado de "assistir alguém" e de "assistir", tanto no sentido de tomar parte em, interessar-se por, quanto no sentido de defender os interesses de outrem; quando se trata de coisas, o verbo adesse tem um significado impessoal de estar aí, haver.
} 
separação entre o permanente e o mutável, a essência e a aparência, o universal e o singular, o inteligível e o sensível, o modelar, que vale como o normativo, de um lado, e, de outro, o modelado, que se submete à norma, etc. Aristóteles ainda tenta recuperar esta tensão criadora de identidade e

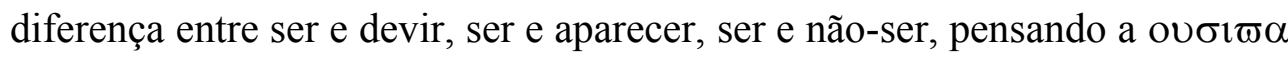
(ousía), a presença do presente, a vigência do vigente, a partir da sua proveniência, a saber, a partir da revelação da $\phi \cup \varpi \sigma ı \sigma$ (physis), tal como se projetara no início do pensamento grego, em referência à $\kappa \iota \varpi v \varepsilon \sigma \iota \sigma$ (kínesis), movimento e mobilidade, tornando-a visível como $\varepsilon \varphi v \varepsilon \varpi \rho \gamma \varepsilon ı \alpha$ (enérgeia), o estar-em-obra, e como $\varepsilon \varphi \nu \tau \varepsilon \lambda \varepsilon \varpi \chi \varepsilon ı \alpha$ (entelékheia), a consumação deste estar-em-obra. A obra é, aqui, aquilo que passou do nãoser para o ser, da não presença e não vigência para a presença e vigência, o que veio a ser, que se erigiu, crescendo e aparecendo, apresentando-se estavelmente no desvelado, no desencoberto e, deste modo, o seu surgir,

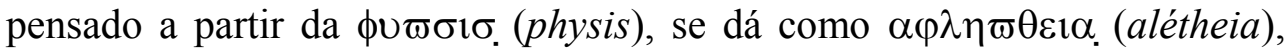
desencobrimento. A obra é, pois, uma presença, algo que repousa em si mesmo, numa estabilidade, numa subsistência, numa quietude (Heidegger, 1998b, p. 368-369).

Na romanidade, antiga e medieval, a $\pi \alpha \rho o v \sigma ı \varpi \alpha$ (parousía), ou seja,

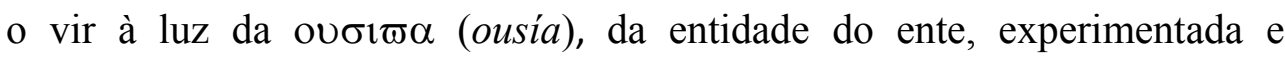
compreendida como o perdurar da vigência do vigente ou presença do presente, perde de vista o seu caráter de $\alpha \varphi \lambda \eta \varpi \theta \varepsilon i a ̣$ (alétheia). A potência produtora, isto é, condutora e consumadora, própria da $\phi v \varpi \sigma l \sigma(p h y s i s)$, se retrai em seu caráter poético e manifestador, e em seu lugar entra o poder do "facere", com o seu caráter de "industria" (atividade, trabalho, labor). O ente passa a ser experimentado e compreendido como o "opus" (obra) de um "operari" (pôr em obra, operar), como o "factum" (feito, fato) de um "facere" (o fazer laborioso), o "actus" (o impelido) de um "agere" (impelir para adiante). Em concordância com isso, o ser do ente, a sua entidade, 
passa a ser experimentada e compreendida como "actualitas", o caráter de ser do "actus", com a sua potência ativa, que impele algo a "existere", a existir, isto é, a vir para frente e para fora, saltando do nada e das causas para o todo do ente enquanto mundo (cf. Heidegger, 1998b, p. 374-383). "Esse est actualitas omnium actuum", diz Tomás de Aquino (De potentia, q. 7, a. 2, ad 9: apud Fontanier, 2007, p. 12). Numa tradução-interpretação que tenta captar o espírito da língua latina, se pode dizer: ser é a atualidade de todas as coisas atuadas, a realidade de todas as coisas realizadas, a impulsão de todas as coisas que são impelidas a existir.

Na modernidade, a $\pi \alpha \rho o v \sigma ı \omega \alpha$ (parousía), ou seja, o vir à luz da ov enquanto atualidade ou realidade, apresenta o sentido de ser da efetividade do efetivo e da objetualidade do objeto. Na realidade enquanto efetividade (Wirklichkeit) está latente o efetivar e o ser eficiente (Wirken) e, portanto, a causalitas (causalidade) (cf. Heidegger, 1998b, p. 431).

Na idade média a causalidade era compreendida de modo quádruplo: como causa materialis (causa material), aquilo a partir de que a obra se perfaz; como causa formalis (causa formal), a forma que informa a configuração da obra e que determina a matéria inserindo-a em si; a causa finalis (causa final), o fim a que a produção da obra tem em vista e por causa de que ela é realizada; e a causa efficiens (causa eficiente), o agente que efetua a obra, reunindo com sua arte, isto é, com o seu saber inventivo, que inclui a reflexão, as causas intrínsecas, a formal e material, na entidade una da obra, tendo em vista o seu fim (cf. Heidegger, 1997, p. 11-12; Heidegger, 2001, p. 13). Esta doutrina tradicional, firmada no horizonte da compreensão artesanal da realidade e do saber sobre esta realidade, tem origem na essência grega da causalidade, só que esta origem permanece

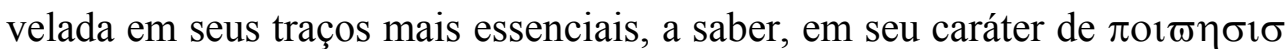
. (poíesis), pro-dução, e de $\alpha \varphi \lambda \eta \varpi \theta \varepsilon ı \alpha$ (alétheia), desencobrimento. $\mathrm{Na}$ experiência e na compreensão grega, as quatro causas são quatro modos de 
responder pelo surgimento da obra, e, por conseguinte, do seu vir à luz e aparecer, na passagem do ser-latente para o ser-patente, manifesto. São, ademais, quatro condições da produção, a que a coisa deve a sua consumação, na passagem do não-ser (não-viger; não-estar-presente) para o ser (viger, estar presente), bem como da possibilidade enquanto

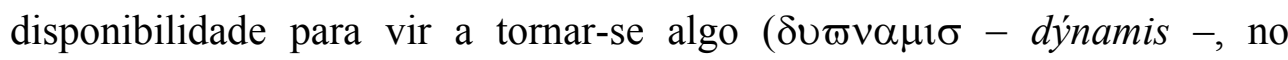
sentido de potência passiva, receptiva) para a consumação deste devir na $\varepsilon \varphi v \varepsilon \varpi \rho \gamma \varepsilon 1 \alpha$ (enérgeia), no estar-em-obra, e na $\varepsilon \varphi \nu \tau \varepsilon \lambda \varepsilon \varpi \chi \varepsilon 1 \alpha$ (entelékheia), perfeição enquanto plenitude do estar-em-obra. $\mathrm{Na}$ compreensão e experiência grega, o saber inventivo, criativo, poético, a $\tau \varepsilon \varpi \chi \vee ̣ ̣$.tékhne) é um modo constante de se ater à produção das obras, uma capacidade produtiva habitual, adquirida com a experiência, que é

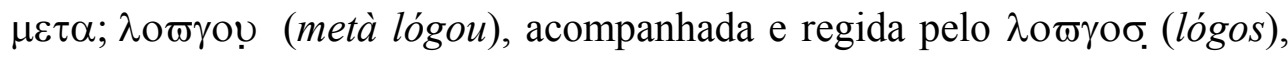

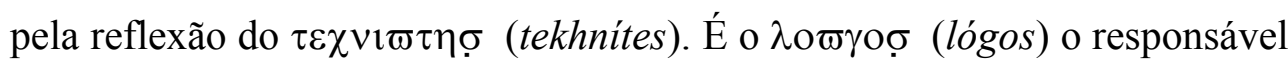
por pôr a matéria na definição de um aspecto ou figura ( $\mu \circ \rho \phi \eta \varpi-$ morphé) e por conduzir à obra à sua consumação, segundo o seu sentido e fim (cf. Aristóteles, Física, II, 193a 28-193b 20; Heidegger, 1996, p. 275-282). É ele o responsável por recolher e reunir as causas no acontecer da produção, dando à entidade da obra um caráter unitário e, ao mesmo tempo, único, singular. Por ele, o comum, a universalidade, não exclui, antes, se inclui, na singularidade do individual, isto é, do que é cada vez um e único ( sentido primordial e eminente $(\pi \rho \omega \ni \tau \eta$ ov $\sigma \iota \varpi \alpha-$ prote ousía $)$. Em todo o caso, a essência grega da causalidade é experimentada e compreendida como um causar e ocasionar no sentido de provocar o surgimento e de originar, e este, no sentido de deixar-viger, de deixar vigorar numa presença, deixar ser presente no desencoberto (cf. Heidegger, 1998b, 869).

Tudo isso, porém, está encoberto e esquecido na experiência e compreensão moderna da causalidade enquanto efetuação e efetivação de um fazer industrioso que visa obter resultados e de um agir impelente, que 


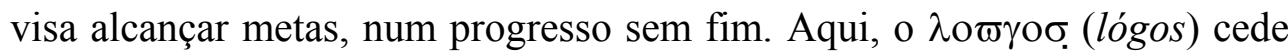
lugar à ratio (razão), enquanto pensamento que percebe, representa e que calcula. No efetuar atua o pensar como actus do ego cogito, enquanto repraesentare. Este ego cogito, por sua vez, se torna subiectum, fundamento de representação de todo o ente, o qual é agora entendido como objectum ${ }^{2}$. Isto quer dizer: o ente, o presente, se torna agora o que é representado por um ego. O ser é agora experimentado e compreendido como objetualidade (Gegenständlichkeit), vale dizer, como representatividade (Vorgestelltheit) no sujeito. Trata-se, porém, de um sujeito que procura alcançar a segurança para si assegurando-se da evidência do objeto e sobretudo da evidência de si mesmo como sujeito por meio da verdade enquanto certeza. A actio (ação, atuação) de cada subiectum, o seu repraesentare, se desdobra, por sua vez, em perceptio (apreensão, percepção) e appetitus (apetite, desejo, pretensão de alcançar alguma coisa). Nesta actio e em sua actualitas atua uma vis primitiva affectiva (força primitiva afetiva), que constitui um traço essencial do subiectum (cf. Heidegger, 1998b, p. 401). No fundo, em todo efetuar o sujeito parte de um representar, que tem o duplo caráter de perceber e de apetecer, e em todo o efetuar o sujeito procura efetuar-se a si mesmo e assegurar-se de si mesmo. O representar se funda na reflexão, no retorno a si mesmo. Na reflexão, a vida da alma e o saber de si desta mesma alma, se transformam em consciência e autoconsciência. O representar, isto é, o tornar presente, pondo diante de si algo como algo, se dá à medida que a consciência retorna para si, remete-se de volta para si mesma, fornecendose, antes de tudo, a si mesma para si mesma. O que está em jogo, portanto, no representar do sujeito, em toda a relação com toda a objetividade, seja do ente que ele não é, seja do ente que ele mesmo é, é a sua autoprodução e seu autoasseguramento em sua subjetividade. O que está em questão é, pois, o

2 "Objectum" é particípio passivo neutro do verbo objicere: jogar em face de, diante de. Objectum seria, portanto, o que está jogado em face, lançado diante de [...]. Grosso modo, esta palavra latina corresponde ao termo grego "antikeímenon". Com este termo Aristóteles designava os correlatos das faculdades da alma (De Anima 402b, 415a). 
querer-se a si mesmo do sujeito e, assim, o seu pôr-se de pé a si mesmo e o seu pôr-se a si mesmo diante de si mesmo. A actualitas acaba por se revelando como voluntas, como vontade, isto é, como um querer que quer a si mesmo, pelo qual o sujeito que se autoassegura e se autoproduz. A passagem do eu para os eus, do indivíduo para os grupos e a sociedade não altera substancialmente este modo de ser, pois esta mesma dinâmica da subjetividade se repete em vários níveis de comunidade, socialidade, coletividade.

O ser do ente, a actualitas, a realidade efetiva, se desdobra pois como a correspondência funcional de efetuar e ser-eficiente, de ser-representado e representar, de ser-apetecido e apetecer, assumida numa vontade que quer a si mesma, numa vontade que é, progressivamente, vontade de saber, vontade de amor, vontade de poder, e, enfim, vontade de vontade. A vontade é o que une subjetividade e objetividade na sua correlação e correspondência (cf. Heidegger, 1998b, p. 430-436). A vontade é a função que unifica todo o ente numa conjunção essencial, chamada sistema. Assim como a antiguidade e a idade média foram as épocas da substância, a modernidade é a época do sistema. A vontade de sistematização de tudo instala o mundo. Subjetividade significa, então, instalação do mundo. Mundo aparece agora como instituição, organização, rede de relacionamentos funcionais. É, então, a hora e a vez da "maquinação".

\section{A técnica como figuração da entidade do ente: a maquinação e} sua luz dúbia

"Maquinação" nomeia (Machenschaft) o senhorio do fazer (Machen) e do feito (Gemächtes) sobre todo o ente (cf. 1994a, p. 131). É uma figura da entidade do ente no seu todo, que se desprendeu na era da consumação da metafísica como vontade para o poder (Macht). É a mais extrema liberação (Loslassung) do ser na entidade, em que se dá o predomínio do real efetivo como o que é calculável, planificável, organizável, executável. Por esta 
liberação, o ser chega à sua mais extrema abdicação em favor do predomínio da entidade do ente e de sua inessência (Unwesen) (Cf. Heidegger, 1998b, pp. 15 e 445-446). A origem desta liberação já se

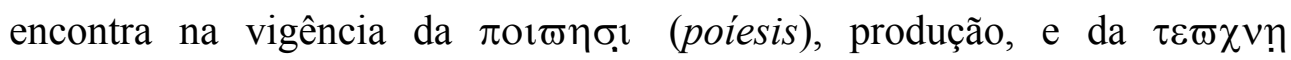
(tékhne), produção sapiente e sapiência produtora. O caráter de "inessência" (Unwesen) da entidade como maquinação está implícita na própria palavra "Machenschaft", embora Heidegger tome esta palavra como um título ontológico. A palavra "Machenschaft", no discurso cotidiano, tem o sentido de intriga e de manobra. A palavra é pensada por Heidegger, entretanto, em sua relação com o verbo "machen" (fazer) e com os seus produtos (Gemächtes) ${ }^{3}$. Os dois sentidos, o cotidiano e o do pensamento, porém, se conectam, na medida em que os produtos do fazer, isto é, os feitos e os fatos do agir, inclusive tudo aquilo que se chama de cultura e seus valores, e, por conseguinte, os feitos do fabricar, os artifícios, os artefatos e as artimanhas da engenhosidade humana, são impregnados de fetichismo. Há em tudo isso um poder "mágico". Neste sentido o uso da palavra "Machenschaft" (maquinação) também remete a poder $(M a c h t)^{4}$, ao poder do fazer, certamente, com toda a sua taumaturgia, mas também com todas as suas ilusões.

O uso da palavra "Machenschaft" (maquinação) está, porém, calcado no próprio uso da palavra $\tau \varepsilon \varpi \chi \nu \eta(t e ́ k h n e)$. Esta palavra designa,

\footnotetext{
${ }^{3}$ Confira o comentário de Heidegger sobre a distinção feita por Aristóteles entre $\phi v \varpi \sigma ı t s$ (phýsis) e $\tau \varepsilon \varpi \chi \vee \eta$ (tékhne), entre $\phi \cup \varpi \sigma \varepsilon \imath ~ o \varphi v \tau \alpha$. (physei onta) e aqueles entes que são produtos da técnica - $\alpha \varphi \pi \mathrm{o} ; \tau \varepsilon \varpi \chi \vee \eta ̣$ (apó tékhnes), em Física, II, 192b 1-23, em "Vom

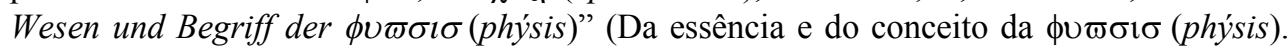

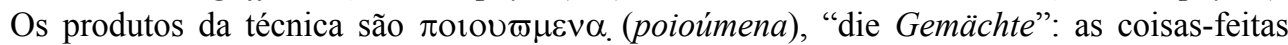

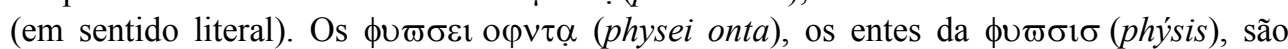
"die Gewächse", em sentido amplo, não só como plantas, mas também tudo aquilo que cresce a partir de si. Para Heidegger, seria uma má compreensão compreender o ente natural no horizonte da compreensão da autofabricação (Selbstherstellung). Ele põe em evidência que o conceito de organismo e de orgânico é um conceito mecânico-técnico que estendemos aos viventes (Cf. Heidegger, 1996, p. 250-255).

${ }^{4}$ A palavra "Macht", poder, potência, remete ao verbo vermögen, poder, no sentido de ser capaz de, e remonta à raiz indo-germânica magh, de onde vem a palavra "magia" (conforme nota de Franco Volpi em Heidegger, 1995, p. 1009).
} 
propriamente, um produzir sapiente (wissendes Hervor-bringen) (cf. Heidegger, 1987, p. 16); um saber produtor que põe algo no mundo (cf. Heidegger, 1998c, p. 213) ${ }^{5}$. Mas significa também a sagacidade deste saber como perícia, habilidade e competência; e, por conseguinte, ofício e arte, com seus respectivos modos de proceder. Significava também estratagema, expediente, astúcia, e, enfim, cilada, tramoia, engano. Pode-se pensar, por exemplo, no cavalo de Troia e na caixa de Pandora. Assim, a $\tau \varepsilon \varpi \chi \vee \eta(t e ́ k h n e)$ não se revela apenas como $\sigma o \phi ı \varpi \alpha$. (sophía), saber,

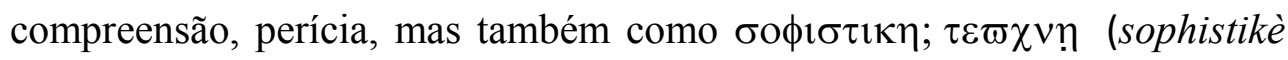
tékhne), no sentido pós-platônico desta expressão, isto é, como artimanha

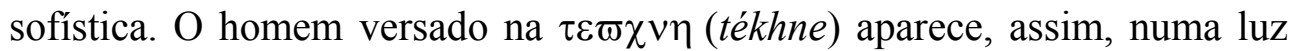
dúbia, ambígua. Ele não aparece simplesmente na univocidade do ser de um бофош̣ (sophós), um sábio, no sentido de ser um homem experto, um perito, um sagaz, mas sim na ambiguidade de ser um $\sigma o \phi \imath \sigma \tau \eta \varpi \sigma$ ( (sophistés), um sofista, ou seja, a ambiguidade de poder ser um sábio, no sentido de ser hábil artífice, um perito e experto, mas de poder ser uma mera aparência do sábio, do homem filósofo em sentido próprio, ou seja, poder ser um sofisticado enganador, um charlatão. Por isso, a sofisticação da maquinação tem não somente o sentido de virtuosidade e sutileza da engenhosidade, mas também o sentido de sofisma, de adulteração, de falsificação, de tapeação. Há nestas duas palavras, portanto, uma conotação do que hoje, no mundo virtual da sociedade em rede, se chama de fake (em inglês, algo de falso, de fingido).

A essência da técnica é, assim, não só uma forma de verdade, de desencobrimento do ente, mas também uma forma de não-verdade, não a do encobrimento como mistério, mas a da errância e da dissimulação (Verstellung) (cf. Heidegger, 1996, p. 196-198; 1999, p. 164-166). A entidade aparece não só como essência, no sentido de essencialização

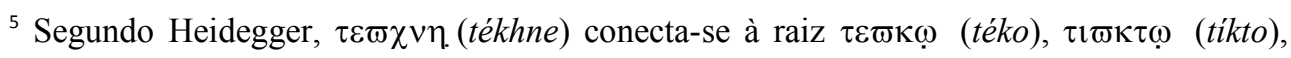
procriar, criar, no sentido de parir, dar à luz, "colocar no mundo".
} 
(Wesen, em sentido verbal), mas também como inessência (Unwesen), isto é, como perda do vigor de essencialização e o avesso da essência. Ela não somente é um encaminhamento do sentido de ser, mas também um descaminho e uma errância. Assim, a técnica como modo de ser e de saber hegemônico do homem moderno, em sua luz dúbia e ambígua não somente é a consumação da filosofia, a filosofia operativa sonhada por Descartes ${ }^{6}$, mas também a mais sofisticada vigência da sofística. A técnica é, pois, a filosofia e a sofística de nosso tempo. A sua luz, que ilumina nosso modo hegemônico de ver o ente no seu todo, é uma luz de néon. No brilho de seu progresso e de suas novidades, com efeito, não somente somos iluminados, mas essa própria iluminação da técnica como a luz óbvia em que vemos todo o ente, nos obscurece a vista não nos deixando ver as estrelas da noite do mistério do ser, que, encoberto pela primazia do ente e do pensamento representador e calculador, só pode se dar mesmo como um nada, um zero à esquerda, algo que não conta.

$\mathrm{Na}$ semântica de $\tau \varepsilon \varpi \chi \vee \eta$ (tékhne), portanto, está não somente o encaminhamento do saber produtor e da produção sapiente, mas também a errância da astúcia, da artimanha e da tramoia, o encantamento que prende o homem, encantamento produzido por aquilo que é factício. Neste sentido, o tempo da técnica não é propriamente o tempo do desencanto. É sobretudo o tempo do encanto, no sentido do encantamento, isto é, do feitiço, do

\footnotetext{
${ }^{6}$ Com a moderna vigência e compreensão da realidade em seu todo (subjetividadeobjetividade) como sistema, o saber da totalidade, a "mathesis universalis" se apresenta como "filosofia prática", prática, no sentido de operativa, não especulativa. No seu Discurso do Método (1637), Descartes declara a respeito dos princípios da ciência, o seguinte: “... [eles] convenceram-me de que é possível chegar a um conhecimento da máxima utilidade para a vida e de que, em lugar desta filosofia especulativa ensinada nas escolas, poderemos encontrar uma filosofia prática, com que, conhecendo a força e a ação do fogo, da água, do ar, dos astros, dos céus e de todos os outros corpos que nos rodeiam, tão bem como conhecemos as diferentes artes de nossos artistas, poderemos utilizá-los para todos os fins a que se prestam, e nos tornar assim mestres e senhores da natureza" (cf. Descartes, 1999, p. 206-209). A "filosofia prática" de Descartes não é propriamente uma filosofia da práxis, mas sim uma filosofia da técnica, uma filosofia operativa, que, por fim, suprime a própria diferença de teoria e prática no advento da tecnociência. Com este advento, os homens pretendem ir além de Descartes e não somente se tornarem "mestres e senhores da natureza", mas também "mestres e senhores da história".
} 
fetichismo, com os produtos técnicos e com a sua taumaturgia. O Odisseu dos tempos modernos se vê, pois, envolvido no círculo de Circe, que é o círculo mágico da vida como produção e consumo, como progresso que se retoma infinitamente, não importando se esse progresso pode se tornar um progressivo distanciar-se de nós mesmos e da fonte de toda a criação.

Há que se notar, entretanto, que Heidegger usa o termo "Machenschaft", maquinação, como título ontológico. Como tal, "maquinação" nomeia o todo do ente em sua verdade, a entidade que é instituída e instalada com vista à factibilidade (Machsamkeit), ou seja, a entidade do ente, a vigência em que tudo é primeiramente constituído e estatuído como factível em vista da sua factibilidade (cf. Heidegger, 1994a, p. 14). É na vigência da maquinação, enquanto nome para a entidade do ente, que o homem agencia e empreende o domínio do ente como um todo por meio do cálculo. $\mathrm{Na}$ totalidade do sistema a entidade do ente como um todo se apresenta como factibilidade constituível (ausmachbare Machbarkeit) a serviço da produção total e infinita. Total é aquela produção que tem como meta produzir tudo, inclusive as próprias condições que tornam possível a produção. Sua perspectiva de segurança absoluta a torna totalitária. É na perspectiva desta vigência da entidade do ente que o homem enquanto sujeito (eu ou nós), planeja, calcula e decide o que vale a pena representar, fabricar e operacionalizar: produtos técnicos, obras de arte, instituições, ordenamentos comunitários, sociais, coletivos, etc. É nesta perspectiva que ele, enquanto Homo Faber, estima e instaura os valores culturais e cultiva as visões de mundo (cf. Heidegger, 1998b, p. 15). O ser como um todo, a presença de todo o presente, passa a ser, pois, encarado na perspectiva da fabricabilidade (Hergestelltheit), ou seja, da capacidade de pôr no mundo algo que podemos trazer para junto de nós, que podemos representar, manobrar e manusear, controlar, dominar, desfrutar e consumir. O ente como um todo apresenta-se como o que está disponível para o fazer no sentido do fabricar humano, e isto quer dizer, por sua vez, o que está 
disponível para o asseguramento da subsistência ou sobrevivência humana. Neste sentido, torna-se decisivo para o homem o superpotenciamento do cálculo, da computação, da técnica combinatória de dados e informações. Correspondendo a esta constituição do mundo na perspectiva da maquinação o representar passa a ser o medir calculador, assegurador, que, passo por passo, mede os horizontes que delimitam todo o perceptível, o seu ser passível de explicação e a sua utilização.

À maquinação acrescenta-se, porém, outro traço essencial, aparentemente oposto, mas que lhe pertence de forma geminada: a vivência (Erlebnis) (cf. Heidegger, 1994a, p. 131-134). É que na perspectiva do homem que se encontra a si mesmo como vivente racional (que calcula, planeja, institui, instala, fabrica, apronta mundo), entra não somente o representado como o calculável, o computável, mas também como o vivido e vivenciável. No tempo da maquinação, vale como ente somente aquilo que o homem pode trazer para si e diante de si como vivenciável. Ambas, maquinação e vivência, se pertencem, no modo como o homem empreende seus relacionamentos para com toda realização e com todo o real, enquanto vivente racional. Característica comum de ambos é o não conhecer limites, o estar a serviço do ilimitado progresso e do ilimitado domínio do homem, enquanto sujeito, sobre tudo. É na perspectiva da maquinação, isto é, do poder e sagacidade do fazer e do feito, da fabricabilidade e da factibilidade, e da vivência, que o homem se apropria das coisas, de si mesmo e dos outros, do que pertence à esfera pessoal e dos ordenamentos comunitários e sociais, com sua publicidade, bem como dos valores culturais. Com efeito, mesmo os domínios criativos do espírito, como arte, religião, filosofia, são absorvidos na perspectiva da instrumentalidade e do gozo, como meios para os fins de domínio, isto é, de controle e de desfrute vivencial do homem sobre o todo do ente. 
IV. O real como disponibilidade (Bestand) e a realidade como composição (Gestell). A linguagem como informação

$\mathrm{Na}$ factibilidade vigora o fazer, no sentido do fare, do produzir laborioso. $\mathrm{Na}$ língua latina, em sentido próprio e originário, o verbo fare significava pôr, colocar; só a partir daí é que veio a significar fazer, no sentido de executar, provocar, exercer, praticar, trabalhar, fornecer. Fundada na entidade do ente entendida a partir da causalidade, efetividade, factibilidade e fabricabilidade, a técnica moderna é um desencobrir o ente na perspectiva de um pôr, que tem o modo de ser do provocar (Herausfordern) ou explorar (cf. Heidegger, 1997, p. 18; 2001, p. 18-19). É um pôr que impõe à natureza a condição de fornecedora de energia a ser beneficiada e armazenada, no horizonte da disponibilidade do que pode ser encomendado para o trabalho transformador do homem. No horizonte desta disponibilidade o ente se torna um estar a postos para ser disposto, portanto, recurso, insumo, encomenda, algo a ser provocado, isto é, trazido para fora numa exploração e impelido para adiante num processamento. Na ótica da disponibilidade, portanto, todo o ente, todo objeto (Gegenstand), natural ou artificial, natural ou cultural, objetivo ou subjetivo (coisas da natureza, artefatos e instrumentos, aparelhos e máquinas, mas também homens e suas vivências, instituições e ordenamentos sociais, Estado, setores e valores da cultura), se torna dispositivo (etwas Bestelltes), ou seja, algo disposto como encomenda e recurso para a exploração e o processamento da produção total e seu progresso infinito, que visa se assegurar cada vez mais da estabilidade e segurança no tocante à sobrevivência e da subsistência humana. Tudo é, pois, visto na ótica da disponibilidade (Bestand). Esta palavra é tomada, aqui, como uma categoria ontológica, que designa "o modo em que vige e vigora tudo que o desencobrimento explorador atingiu" (Heidegger, 1997, p. $20 ; 2001$, p. 21). Na verdade, neste novo sentido de ser da entidade, o ente já não é mais simplesmente objeto, algo que está diante de nós (Gegenstand) num representar, mas passa a ser dispositivo da disponibilidade, ou seja, 
algo que está disposto em função do asseguramento das possibilidades da subsistência humana (Bestand). A realidade tomada no sentido do que reúne todo o real e suas realizações na ótica da disponibilidade; o que, nesta mesma ótica reúne todo o ente (real) como dispositivo, e reúne todos os modos de pôr (realizações) como disposição (Bestellung), é chamada por Heidegger de Gestell, composição. "Composição", "Gestell", significa a força de reunião (das Versammelnde) daquele pôr (Stellen) que põe, ou seja, que desafia o homem a des-encobrir (entbergen) o real no modo da disposição (Bestellen), como disponibilidade (Bestand)" (Heidegger, 1997, p. 24; 2001, p. 24).

Este desencobrimento explorador, que põe, isto é, provoca e desafia o próprio homem, como um apelo, uma reivindicação e uma exigência (Anspruch) que se lhe impõe, requer continuamente o controle e asseguramento de tudo. A este apelo responde a ciência moderna, que é essencialmente técnica, isto é, que é filosofia operativa. Nela, não está em jogo o saber essencial, fundamental e universal da realidade, mas o conhecimento enquanto forma de domínio do real. O conhecimento produzido não precisa ser verdadeiro, no sentido do desvelamento do essencial, basta ser correto, no sentido da consistência sistemática e da eficiência e eficácia produtiva, no assegurar o domínio da natureza, da história, da linguagem, enfim, do ente no seu todo. Ela é o projeto da razão, do pensamento que calcula, a serviço do domínio do real. A ciência se realiza como um grande agenciamento da pesquisa e um grande empreendimento funcionalizante e sistematizador de todos os recursos da natureza e da história, do mundo objetivo e do mundo subjetivo. Dentre as ciências, decisivas são aquelas que têm o caráter de ciências formais, pois são elas que devem produzir o caráter sistemático de todo o conhecimento material (que tem um conteúdo): A matemática, a lógica, transformada em logística, e, enfim, a cibernética e saberes afins, cumprem esta função (cf. Heidegger, 1988, p. 63-65; 1999, p. 97-98). Estas constituem a 
infraestrutura da razão, no sentido da racionalidade técnica, que opera o controle de todo o controle da informação no processo da produção do real.

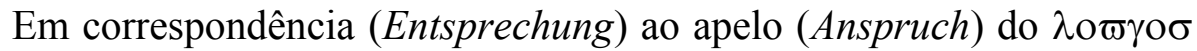
. (lógos) da tecno-logia, isto é, ao apelo da força de reunião (das Versammelnde) da composição (Gestell), o homem passa a compreender a linguagem do real que ele escuta no processamento de suas pesquisas e intervenções produtoras, bem como a sua própria linguagem, que ele exerce e executa como meio de expressão e de comunicação, como informação (cf. Heidegger, 1989, p. 20-28). Do falar que está a serviço do dizer e mostrar, passa-se ao sinalizar que anuncia e noticia algo que por si mesmo não se mostra. A sinalização passa pelo estabelecimento convencional e, por conseguinte, por crescente processo de abstração, formalização e codificação, visando alcançar sempre mais perfeitamente a univocidade. Por isso, a linguagem artificial se sobrepõe à linguagem tradicional. Todo o dizível deve poder estar a serviço do cálculo lógico e das possibilidades de uma comunicação eficiente, segura e rápida. Comunicação deixa de ser o compartilhar da plenitude do mundo (totalidade significativa) no ser-com-ooutro comunitário, para ser a ser transmissão de informações na convivência exercida numa sociedade em rede. Numa escala planetária, toda a comunicação comunica o factível e o vivenciável, num intercâmbio de informações. Toda a informação, por sua vez, é recurso para a informatização, que está a serviço do controle de todo o real. Com isso, se instala o senhorio do virtual (cf. Leão, 2013, p. 219-228). De fato, o virtual está a serviço do controle do real e do atual. O virtual até simula a possibilidade de substituir o real, tanto na dimensão "objetiva" das coisas quanto na dimensão "subjetiva" das vivências. Máquinas e cérebros, imagens e sons, se tornam recursos dispostos para o processamento da linguagem enquanto informação a serviço da comunicação em rede, que, por sua vez, se processa segundo a ótica da factibilidade e da vivência. A informatização pretende alcançar o controle de todas as línguas, artificiais e 
tradicionais, de suas sintaxes e semânticas. Uma questão é se esta pretensão pode alcançar o que pretende. Outra, se justamente o alcançar esta pretensão não significaria o estiolamento da linguagem humana, o esgotar-se das fontes da criação poética e da plenitude da vida simbólica, e se, com este exaurimento, a própria comunicação e convivência humana não sofreria um dano irrecuperável.

\section{A vigência da técnica da educação e o predomínio do negócio sobre o ócio}

Na modernidade impera uma compreensão técnica de toda a educação. A essência, a natureza ou o sentido da própria educação, é compreendida de modo técnico (cf. Leão, 1979, p. 11). A educação é vista como um fazer. Num sentido amplo e fundamental, educação é tudo o que fazemos por nós mesmos e tudo o que os outros fazem conosco, com a finalidade de formar o nosso ser, perfazendo-o, isto é, fazendo-o alcançar a perfeição de nossa natureza humana. Nesse sentido, educação é a efetuação e a efetivação da formação do caráter do homem, implicando todas as dimensões e aspectos do seu ser, o físico, o psíquico, o espiritual, o social, o cultural, etc. Nesta amplitude, tudo o que contribui para esta formação, espontaneamente educa. Somos educados pelo nosso mundo-ambiente, pelas coisas da natureza, pelas interações e relacionamentos de nosso mundo compartilhado mais próximo, constituído pela família e pelas comunidades em que somos inseridos desde criança, pelas instituições sociais e suas atividades, pelas leis e pelo Estado, etc. Entretanto, num sentido menos amplo e menos fundamental a educação aparece como um fazer intencional e sistemático, como uma arte, isto é, como um saber produtivo e uma produção sapiente, que visa o desenvolvimento de toda a perfeição de que o indivíduo é capaz. Num terceiro sentido, em níveis técnicos, a educação aparece como uma ação que diferencia idades, gerações e classes. Ela aparece como atuação exercida pelas gerações adultas sobre as gerações ainda não maduras para a 
vida social. Esta atuação é guiada por objetivos sociais. Ela pretende suscitar e desenvolver na criança certas virtualidades físicas, intelectuais e morais, requisitadas pela sociedade política na qual a criança está destinada a viver. Educação se torna, então, socialização. Educação é ainda a atuação da classe dominante sobre as classes funcionais, de uma elite produtora sobre uma massa consumidora.

Todas estas concepções concordam que a educação é um fazer que almeja uma finalidade e que tem um caráter operativo. Mantendo-se este caráter operativo, há lugar para divergência de conteúdo. Nessa ótica da factibilidade, portanto, a educação se torna a aquisição de padrões mutáveis de comportamento, que tornam mais fáceis reproduzir as formas e modos físicos, imaginários e simbólicos de agir, conhecer e sentir, que permitam a sistematização do sistema. A educação se torna, assim, meio para se alcançar o autoasseguramento da subjetividade instaladora de mundo, independente se esta subjetividade é onticamente realizada como sujeito-eu ou como sujeito-nós. O enquadramento funcional da educação na armação do sistema condiciona as decisões. Estas são tomadas na ótica da produção, da factibilidade, da eficiência, da utilidade, bem como na ótica da vivência e do seu consumo. O que se tem em mente é a subsistência e a segurança desta subjetividade como consciência e autoconsciência. A subsistência, de meio se transforma em fim. E a educação é subordinada, funcionalizada, colocada a serviço desta finalidade. Ela se torna dispositivo a serviço da segurança da subsistência.

Nesta perspectiva, muda o sentido fundante da escola: este deixa de ser o ócio e passa a ser o negócio (cf. Fernandes, 2012, p. 48-57; Leão, 2013, p. 144-149). Em grego, temos a palavra $\sigma \chi 0 \lambda \eta \varpi . ~(s k h o l e ́)$, que os latinos traduziram para otium. $\Sigma \chi 0 \lambda \eta \varpi ़$ (skholé) significa, originariamente, tempo livre, quietude, repouso, ócio. O seu contrário é $\alpha \varphi \sigma \chi \sigma \lambda \imath \varpi \alpha$ (askholía): falta de tempo livre, impedimento, ocupação, negócio. O $\alpha$ (alpha) privativo, bem como a própria semântica da palavra, dizem que o 
positivo é a $\sigma \chi 0 \lambda \eta \varpi$ (skholé) e que o negativo é a $\alpha \varphi \sigma \chi \sigma \lambda \imath \varpi \alpha$ (askholía). Também a configuração da língua latina o diz: positivo é o otium, negativo, o que nega, é o nec-otium, o não ócio, o negócio. Este estado de coisas, esta conjuntura e situação, é também testemunhado(a) pela sentença de Píndaro, que diz:

$\tau \varepsilon \varpi \lambda \circ \sigma \gamma \alpha ; \rho \varepsilon 1 \varphi \rho \eta \varpi v \eta \mu \varepsilon ; \nu \pi \mathrm{o} \lambda \varepsilon \varpi \mu \rho \nu, \sigma \chi 0 \lambda \eta ; \delta \varphi \alpha \varphi \sigma \chi 0 \lambda 1 \varpi \alpha \sigma$ (télos gàr eiréne mèn polémou, skholè d'askholías): "o sentido do combate é, pois, a paz; o do negócio, o ócio".

Aliás, Píndaro não está sozinho neste testemunho: vem acompanhado de Aristóteles. Em consonância com Píndaro ele diz:

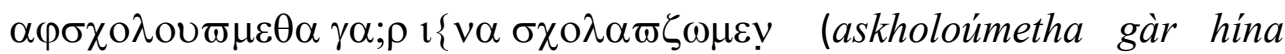
skholádzomen), "nos empenhamos, nos ocupamos e preocupamos com os negócios a fim de ter ócio".

O ócio é aqui a expressão do tempo livre: livre dos impedimentos das ocupações e das preocupações pela subsistência e segurança; livre para a criação do espírito, isto é, para as brincadeiras, os folguedos, os jogos, as festas e os festivais, para pôr em obra a verdade e a beleza do ser na poética das belas artes, livre para o culto, para a contemplação e o pensamento. Tanto no sentido da liberdade negativa, desimpedimento das ocupações e preocupações da sobrevivência, quanto no sentido da liberdade positiva,

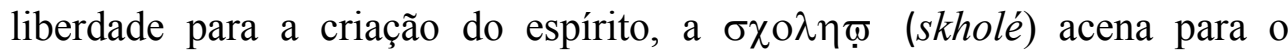
mistério da gratuidade e para a gratuidade do mistério, como sendo superior a todo o útil e inútil das coisas e dos haveres, bem como a todo o mérito e demérito do homem. Da confraria de Pitágoras, dedicada ao culto das musas, filhas de Mnemosyne (deusa da memória) e de Zeus (deus do raio), ao Katholikon Mouseion dos bizantinos, por um lado, e à "universitas studiorum" ou "universitas magistrorum et discipulorum" dos latinos, as escolas de educação superior eram confrarias dedicadas ao culto. Todo o estudo acadêmico, todo o trabalho intelectual, visava cultivar o espírito humano para render homenagem à verdade, ao bem, ao belo, ao uno, ao ser, 
em última instância, ao divino no cosmos, na alma, em si mesmo. Assim,

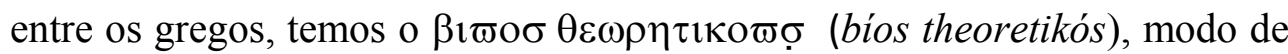
viver dedicado ao olhar que contempla o extraordinário do mistério vigente em todo o ordinário, as cintilações do mistério do ser, como em Heráclito, ou ao cultivo do que há de divino no homem, o vо৩эб (noûs), o pensamento que percebe o ser, como em Aristóteles. E, entre os latinos, temos a vita contemplativa (vida contemplativa) segundo o culto da religião cristã. Esta subordinação do negócio ao ócio reinou, pois, como princípio ético da existência da humanidade ocidental, até o advento da modernidade.

No mundo moderno, inverte-se o princípio. O ócio é que está a serviço do negócio. A cultura está a serviço da economia. A religião e a arte, tornadas formas de vivência, no sentido da produção e do consumo simbólico; o lazer, tornado divertimento e entretenimento; o jogo, tornado desporto profissionalizado e mercantilizado; a escola, tornada instituição em que se produz a educação intencional, funcional e sistemática, a serviço da socialização na sociedade da produção; a universidade, tornada escola superior que visa a produção do conhecimento, entendido tecnicamente como know-how, e como lugar de profissionalização para esta sociedade e seu mercado de trabalho; tudo isso se torna subserviente ao negócio. A livre criação do espírito cede lugar então à inteligência da razão instrumental, que crê produzir, com o trabalho de sua racionalidade, o real e o irreal. O conhecimento deixa de ser aceitação da realidade se dando e se subtraindo em seu mistério nas realizações do real e passa a ser a produção do real por meio da pesquisa e das transformações tecnológicas. Não há lugar para a contemplação, somente para a ação, no sentido do fazer que impele tudo para o progresso infinito da produção total. Não há lugar para a intuição intelectual, isto é, para uma atividade silenciosa, receptiva e acolhedora da realidade do real. Todo o conhecimento intelectual deve ser discursivo e produtivo, eficiente e eficaz. É o labor de combinar os dados da percepção, em vista da produção objetiva, funcional e sistemática do real. Trata-se de 
um esforço hercúleo em que está empenhada a racionalidade moderna. A cultura não é outra coisa do que a produção do mundo que se instala a partir deste esforço hercúleo. A educação não é outra coisa do que a socialização neste mundo do sistema da produção total. Neste mundo, todo o bem se nivela ao nível da utilidade e do prazer, e o todo o mal se identifica com a inutilidade e o desprazer ou a dor. Se for não-útil é imediatamente identificado com o inútil. Se é desnecessário para a subsistência e a sobrevivência é por si sem importância. Todo o bem se nivela ao útil da factibilidade e ao agradável da vivência. O nobre e o belo, o justo e o verdadeiro, bem como o sagrado, tudo aquilo que é importante no domínio da liberdade criativa e do mistério da gratuidade, ou é absorvido no horizonte e na dimensão do útil e do agradável, ou é excluído. O bem comum é nivelado à utilidade comum na perspectiva da produção, bem como ao gozo vivencial na perspectiva do consumo. Tudo é insumo para a produção e o consumo de bens e serviços. Não se admite uma dimensão livre e autônoma de criação. As palavras de John Henry Newman, em Idea of University, se tornam palavras de outro mundo: "sei muito bem que o conhecimento pode ser útil para a prática, mas pode também voltar para o espírito, donde nasceu e tornar-se filosofia. No primeiro caso o conhecimento é útil, no segundo, é livre” (apud Leão, 2013, p. 149).

\section{O outro princípio do pensar e a pedagogia da pobreza}

O fim da metafísica na época da técnica é também indica transformação e acena para um outro princípio do pensar. Desde que estamos no fim da era da metafísica na época da técnica, era de um dia histórica que dura cerca de dois milênios e meio, entramos também no hiato entre o primeiro princípio do pensar, fundado na compreensão do ser do ente como ovoløạ (ousía), presença ou vigência constante, e o outro princípio, que está porvir e que só pode ser pressentido num diálogo com o primeiro princípio, tentando pensar o seu impensado, o seu esquecido, o seu não-dito. O que o pensamento de 
Heidegger oferece aos homens deste tempo é, justamente, uma meditação sobre esse impensado e um pressentimento do outro princípio porvindouro. Quiçá, a partir deste pressentimento, abram-se também novos modos de se tomar a tarefa da educação, a educação do e para o pensar que se dispõe ao apelo do outro princípio.

Sob a égide da questão de Ser e Tempo o pensamento de Heidegger convida os homens deste tempo a recordar o esquecimento do ser. Todo o esquecimento é reduplicativo, ou seja, é esquecimento do esquecimento. Por isso, um pensamento que convida a recordar o esquecimento do ser é já um movimento de saída do próprio esquecimento. Entretanto, os homens deste tempo esqueceram-se tanto do esquecimento quanto da memória em seu sentido mais originário, evocado nos primórdios na Mnemosyne do mito grego, a mãe das musas. Para nós a memória é somente uma retenção de dados do passado. Ela é somente retentiva e reprodutiva. Para o mito, a memória é antecipadora e criadora, isto é, está essencialmente voltada para o porvir e suas possibilidades de criação, tanto é que é a matriz e a genitora da múltipla inspiração de que o homem precisa em sua essência inventiva, nascedouro da $\tau \varepsilon \varpi \chi \vee \eta(t e ́ k h n e)$ grega, da "ars" medieval e da técnica moderna.

Pertence à essência do esquecimento esquecer-se de si mesmo. Todo esquecimento é esquecimento do esquecimento. Próprio do esquecimento é retrair-se para si mesmo e imergindo na esteira de seu próprio encobrir-se (cf. Heidegger, 1997, p. 256; 2001, p. 233). Os gregos fizeram a experiência do esquecimento, $\lambda\rceil \varpi \theta n$ (léthe), como encobrimento. $O$ esquecimento é de certa maneira uma latência, um encobrimento. $\mathrm{O}$ verbo $\lambda \alpha \nu \theta \alpha \varpi v o \mu \alpha 1$ . (lanthánomai), em sua forma medial, não significa somente que algo foge da minha atenção, me passa despercebido, permanece ignorado e escondido, mas também que eu não me dou conta, de que eu permaneço encoberto para mim mesmo não só em referência a este algo que me escapa, mas também em referência ao meu próprio esquecimento. $\mathrm{O}$ vigente ou presente se retrai 
como ausente e, neste retraimento, eu mesmo me mantenho encoberto como aquele para quem este presente se retrai. No esquecimento não somente acontece o retraimento de algo para nós, mas também o encobrimento de nós mesmos, bem como de nossa relação com aquilo que esquecemos. Por isso, todo esquecer-se de alguma coisa é também um esquecer-se de si mesmo em relação a isso de que nos esquecemos e um esquecer do próprio esquecimento.

$\mathrm{Na}$ era da metafísica vigora o esquecimento do ser, bem como o esquecimento de nós mesmos em nossa relação com o ser, e, ainda o esquecimento deste próprio esquecimento. $\mathrm{O}$ esquecimento do ser constitui até mesmo a condição habitual em que os homens normalmente vivem a sua vida. De início e na maior parte das vezes, eles se ocupam apenas do ente, como o que é dado ao representar e ao apetecer, ao fazer e ao vivenciar, ao trabalhar e empreender. Nem mesmo se dão conta do ente como ente, ou seja, do ente em seu ser. Com outras palavras, de costume os homens se voltam em suas ocupações e preocupações para com o presente, o vigente, o real, esquecendo-se da presença, da vigência ou realidade como tais. É que a presença não é nada de presente, a vigência não é nada de vigente, a realidade não é nada de real. Por isso, para o homem imerso na sua atitude habitual e absorvido pelo mundo dos seus afazeres, o ser, no sentido da realidade como tal, da presença como tal, da vigência como tal, só pode ser mesmo um nada. A filosofia, enquanto metafísica, tematiza, porém, a

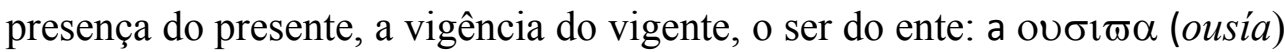
e seus desdobramentos, como $1 \delta \varepsilon \varpi \alpha$ (idéa), como $\varepsilon \varphi v \varepsilon \varpi \rho \gamma \varepsilon ı \alpha$ (enérgeia), como "actualitas", como realidade efetiva, como funcionalidade das correspondências de subjetividade-e-objetividade, ego-e-sistema, como a duplicidade de maquinação-e-vivência, de dispositivo-e-composição, etc. Nunca se dá o presente sem o mistério da presença, o vigente sem o mistério da vigência, o ente sem o mistério do ser. Em seu caráter de mistério, a doação da presença, da vigência, do ser, é sempre oblíqua, indireta, sub- 
reptícia. O homem nunca pode captar o ser como ente. Por isso, o ser é sempre irrepresentável, incalculável, imprestável, para um pensamento que apenas representa, calcula, trabalha. Mas, o que seria o útil e do necessário, se não houve o não-útil e o desnecessário, o livre, o gratuito? Na verdade, nada é mais necessário para o homem do que o desnecessário, o livre, o gratuito. Uma vez Heidegger traduziu um texto do taoísmo que trazia à recordação justamente isso: a necessidade do desnecessário, algo que há muito caiu no esquecimento no ocidente. O texto é um diálogo entre dois mestres, amigos e adversários, e soa assim:

Hui-tzu disse a Chuang-tzu: "Você fala do desnecessário". Chuangtzu falou: "primeiramente carece de alguém reconhecer o desnecessário, antes de poder falar com ele do necessário. A terra é larga e grande, e, no entanto, o homem carece, para ficar de pé, só daquele tanto de lugar necessário onde ele põe o pé. Porém, se, ao lado dos pés, se lhe arrancassem toda a terra, abrindo-se para ele um abismo, aquele tanto de lugar ainda lhe seria útil?”. Hui-tzu falou: "não lhe seria mais útil”. Falou, então, Chuang-tzu: “daí resulta com clareza a necessidade do desnecessário" (apud Heidegger, 1995, p. 239).

Enfim, para um pensar que só se atém ao ente e à sua entidade, o ser, como o não-ente, só pode mesmo ser um nada. Para Heidegger, porém, o niilismo, ao contrário do que costumamos opinar, não é outra coisa do que o esquecimento deste nada. Pensar é pressentir neste nada o não-ente, quer dizer, o ser, agora não mais como a entidade do ente simplesmente, a presença, a vigência, pura e simplesmente, ou seja, pensar é pressentir o ser como diferença que instaura a diferença e referência de ser (entidade) e ente, presença e presente, vigência e vigente. Pensar deixa de ser assim a produção do real e do conhecimento que domina o real. Pensar passa a ser deixar-ser o nada do mistério do ser como diferença originária e originadora 
da identidade e diferença de ser (entidade, presença, vigência) e ente (presente, vigente). Um tal pensar é mais um não-saber do que um saber. Mas, quando o saber se tornou poder, e poder totalitário, o não-saber se torna libertador. Pensar é, pois, acolher o não-saber numa abertura para o nada do mistério e o mistério do nada, que se dá e se retrai na vigência de todo o vigente, em todas as atividades e passividades, ações e omissões dos homens. Do caráter libertador deste pensar nos fala uma outra estória do taoísmo, que aqui adotamos como uma parábola que nos convida a este pensar.

No tempo de mando, desmando e comando da China Imperial, um Imperador Amarelo não possuía a pérola cor da noite. Mandou, então, a ciência pesquisar. Mas debalde a ciência não encontrou a pérola cor da noite. O Imperador mandou a técnica inventar. Mas a técnica também não encontrou a pérola cor da noite. O Imperador mandou a análise calcular. Mas em vão, a análise não encontrou a pérola cor da noite. O Imperador mandou a filosofia investigar. Mas, sem sucesso, também a filosofia não encontrou a pérola cor da noite. O Imperador mandou a arte criar. Mas outro fracasso, a arte não achou a pérola cor da noite. O Imperador achou tudo muito estranho e ficou ainda mais abismado quando, com o tempo, descobriu que o nada que não fora enviado, que não pesquisa, que não inventa, que não calcula, que não investiga, que não cria nada, é a pérola cor da noite. Desde então, o Imperador Amarelo deixou de somente mandar, de somente desmandar, de somente comandar os chineses, para poder no e com o nada ser também a pérola cor da noite" (apud Leão, 2013, p. 212).

$\mathrm{O}$ ente e sua entidade, o presente e sua presença, o vigente e sua vigência se dão ao homem como o que advém no desencoberto. É a partir deste desencobrimento - $\alpha \alpha \varphi \lambda \eta \varpi \theta \varepsilon ı \alpha($ alétheia) - que se dá a

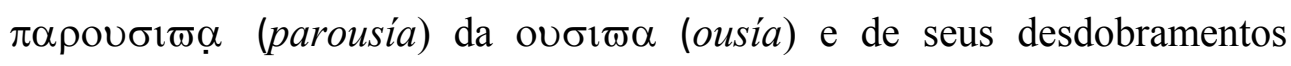


históricos, inclusive a verdade do ente como funcionalidade e, daí, todo o modo de viver do homem moderno na correspondência à interpelação produtiva. A $\alpha \varphi \lambda \eta \varpi \theta \varepsilon ı \alpha$ (alétheia) é a abertura que deixa-ser a iluminação da verdade do ente, com sua realidade e sua aparência, sua essência e sua inessência, sua claridade e suas sombras. Esta abertura descerra e franqueia ao homem as possibilidades de se relacionar com a verdade e a não-verdade do ente, com seu desencobrimento e sua dissimulação. Esta abertura, porém, que é a abertura da liberdade criadora, permanece encoberta para o homem que se atém somente e simplesmente ao ente e à sua entidade. $\mathrm{O}$ apelo desta abertura não nos chega, ultimamente, como o alarido da produção, nem como o alarme dos perigos de destruição que ressoam na consciência planetária dos homens de hoje. É que, para o pensar, o maior perigo não é o da destruição, mas o da desolação, da desertificação, do abandono e do esquecimento das fontes de liberdade e de criação que são dadas para o homem sem nenhum mérito dele, apenas por pura e espontânea gratuidade. A destruição acaba com o que é. A desolação, com o que pode ser. Não resta ao homem, hoje, senão o apelo a perder-se da sua pretensão de onipotência, o que implica também perder-se da sua própria consciência de estar perdido. Perder-se a si mesmo, perder-se da pretensão da onipotência, que visa a total segurança e o controle do controle, e perder-se da própria impotência, confiando-se ao não-saber sapiente e à serenidade do mistério do nada, é condição para encontrar a verdade libertadora. Por isso, o apelo da abertura libertadora e clareadora nos chega, ultimamente, como um clamor silencioso, que conclama o homem a libertar-se para a liberdade da verdade originária, que não é a verdade do ente e de sua entidade, mas a verdade do ser como diferença, como nada, como evento que doa e restitui a cada ente e cada homem o seu ser próprio. Esta libertação é que é a tarefa da educação do pensar e para o pensar do mistério do ser, da $\alpha \varphi \lambda \eta \varpi \theta \varepsilon ı \alpha$ (alétheia). Esta libertação é uma libertação para o não-saber sapiente, ou seja, para aquele não-saber que sabe, isto é, pressente e saboreia no mistério do nada e 
no nada do mistério, o encobrimento como o que abriga e alberga a "pérola cor da noite".

Esta libertação requer do homem um outro modo de habitar a terra. Não mais um habitar baseado nos seus méritos e nas suas demonstrações de poder. É que o pensar do ser renuncia a fazer do poder e, portanto, da potência e da impotência, da conquista e da perdição da segurança da subsistência, o parâmetro de tudo. Este pensar nos conduz para uma outra forma de dimensionar os nossos relacionamentos com o mundo e com a terra, de nos colocar na quadratura de céu e terra, mortais e imortais. Que o homem receba do encoberto, do mistério, as possibilidades de uma nova relação com o desencoberto. Que ele retorne do afã do infinito progresso e da abundância, para o cuidado da finitude e para a pobreza do espírito.

Na crise do século XIV, quando desmoronava o mundo medieval, e lançavam-se as primeiras condições para o surgimento do mundo moderno, Eckhart, a quem Heidegger considerou como um mestre de leitura e de vida (cf. Heidegger, 1977, p. 47), ensinava que pobreza de espírito significa: nada querer, nada saber, nada ter (cf. Eckehart, 1979, p. 303; Eckhart, 2006, p. 287). Talvez poderíamos inverter esta sentença e dizer que pobreza de espírito significa nada poder a não ser o poder que se reconduz ao nada, nada saber a não ser o saber que retorna ao nada, nada ter a não ser o ter que se reenvia à propriedade do ser, quer dizer, ao evento-apropriador, que deixa cada ente e cada um dos mortais ser o que propriamente é, que concilia mundo e terra, cultura e natureza, que recolhe na simplicidade os quatro: céu e terra, mortais e os imortais. E, na sua noite da mente, que parecia antecipar a noite do moderno, Hölderlin disse: "Junto de nós, tudo se concentra no espiritual. Nós ficamos pobres, para nos tornarmos ricos" (apud Heidegger, 1994b, p. 5). Heidegger, comentando este dito de Hölderlin, o poeta da poesia, questiona o sentido usual que damos à palavra pobreza. Nós costumamos considerar pobreza como carência no nível do ter. Para nós, usualmente, pobreza é carecer do necessário. Mas, para o pensador do ser, 
pobreza é algo do ser: pobreza é não carecer de outra coisa do que do desnecessário, isto é, do mistério do ser, que é o encoberto, o mistério da simplicidade, da liberdade e da gratuidade. Somente se libertando para um relacionamento livre com este mistério da verdade do ser, enquanto liberdade e gratuidade, é que o homem pode cuidar de tudo, deixando tudo ser o que é, isto é, o que pode ser em sentido mais próprio. Por isso, o pensar do ser recorda ao homem que ele não está destinado a ser simplesmente o amo do ente. Ele está vocacionado a ser, antes de tudo, o pastor do ser. A ele foi confiado o apelo, que foi trazido à fala no dito de Periandro, um dos sete sábios da Grécia em seus primórdios: $\mu \varepsilon \lambda \varepsilon \varpi \tau \alpha \tau 0 ; \pi \alpha \nu$. (cuida do Todo!). Na compreensão grega, a $\tau \varepsilon \varpi \chi \vee \eta($ tékhne) era, fundamentalmente, $\quad \varepsilon \pi \imath \mu \varepsilon \varpi \lambda \varepsilon \imath \alpha$ (epiméleia), diligência e solicitude do cuidado, com o mundo e com a terra (cf. Heidegger, 1998a, p. 167). Quem sabe, confiando-se ao mistério fontal da liberdade e da gratuidade, o homem reencontre a sua essência de cuidado, de cuidado pelo mundo e pela terra, de diligência e solicitude pelo céu e pela terra, pela sua própria finitude e mortalidade, bem como pelo sagrado e o divino. Assim, ele corresponderia ao apelo do mistério do ser, à fonte da liberdade criadora, que é o livre e o libertador por excelência. A pedagogia da educação do e para o pensar do ser é, pois, a pedagogia da pobreza, que é a pedagogia do cuidado, da liberdade e da gratuidade. "Agora, porém, é justamente o Ser, que todo ente, a cada vez e sempre de novo, deixa ser, o que é e como é, o Libertador, o que deixa cada coisa repousar em sua essência, isto é, o que a cada coisa trata com cuidado e carinho" (Heidegger, 1994b, p. 9). A pedagogia do pensar do ser sabe-se vindo da fonte da gratuidade e da liberdade criadora, que, como evento-apropriador, deixa-ser cada coisa no seu próprio, e dela quer sempre de novo receber na sua pobreza essencial. A pedagogia do pensar do ser quer ser apenas uma pedagogia da pobreza essencial, da pobreza do espírito. 
Com a época da técnica, em que a cultura ocidental europeia se torna planetária, consuma-se a era da metafísica. É o triunfo e, contemporaneamente, a miséria do homem para quem a pobreza e a riqueza fontal do ser estão encobertas e esquecidas. Para este homem a pobreza não é senão carência do ter. Mas, para o pensar do ser, a pobreza pode ser ainda a pobreza do espírito, a pobreza que não carece a não ser do desnecessário, da liberdade e da gratuidade fontal do ser. O fim da metafísica na época da técnica é também o fim da cultura ocidental europeia e de seu domínio planetário? O pensar do ser, a educação como libertação que se liberta para a sua verdade, e a pedagogia da pobreza poderá ser uma via do porvir? Nessa via poderão ser enviados e aviados os povos do sul e do norte, do leste e do oeste da terra? Aprenderão eles um outro modo de habitar a terra? Não convém escutar agora a palavra de Hölderlin, que diz: "cheio de méritos, mas poeticamente, o homem habita esta terra"? (cf. Heidegger, 1997, p. 185; 2001, p. 168) Terminemos, pois, com uma fala deste poeta, que, para Heidegger, era o poeta da poesia. Que estas palavras nos recordem que toda ação e toda produção se sustentam na condução poética do não-ser ao ser e se dá como desencobrimento a partir do encobrimento. Que ela recorde que a abertura da clareira deixa ser a luz do céu e, com ela, toda iluminação da terra, com suas clarezas e suas sombras, seus dias e suas noites.

Ó luz celeste! Não me ensinaram os homens. Já vai longe o tempo em que, meu coração ardente não sabendo encontrar a terra toda viva, me voltei para ti e, confiante como a planta, abracei-me contigo longa e cegamente em minha alegre piedade. Pois um mortal mal reconhece os Puros. Mas, quando o espírito floresceu em mim, como tu floresces, eu te reconheci e gritei: estás viva. É porque viajas entre os mortais e, jovial, como céu, lanças de ti a graça de raios brilhantes sobre cada coisa, para que todas elas tenham a cor de teu espírito, foi por isso que também para mim a vida se fez poesia. É que em mim 
estava tua alma. E assim como tu, meu coração se entregou livremente à terra grávida, à terra sofredora. E, muitas vezes na noite santa, prometi amá-la fiel e sem medo até à morte, amar esta terra, toda carregada de destino, e não desdenhar nenhum de seus mistérios (apud Leão, 2013, p. 180-181).

\section{Referências}

ARISTÓTELES. (1995). Fisica. Milano: Rusconi. . (2005). Órganon. Bauru: Edipro.

DESCARTES, R. (1999). Discours de la Methode / Discorso sul Metodo. Milano: Rusconi.

ECKEHART, M. (1979). Deutsche Predigten und Traktate. Zürich: Diogenes.

ECKHART, M. (2006). Sermões Alemães. Bragança Paulista / Petrópolis: Ed. Universitária São Francisco / Ed. Vozes.

FERNANDES, M. A. (2012). Skholé: o sentido fundante da escola. Em COELHO, Ildeu Moreira (org.), Escritos sobre o sentido da escola (pp. 33-57). Campinas-SP: Mercado das Letras.

FONTANIER, J.-M. (2007). Vocabulário latino da filosofia. São Paulo: Martins Fontes.

HEIDEGGER, M. (1977). O caminho do campo (1949). Vozes, Petrópolis-RJ, Vol. 71, n. 04, p. 46-48, maio 1977. . (1987a). Einführung in die Metaphysik. Tübingen: Max Niemeyer. - (1987b). Introdução à Metafísica. Rio de Janeiro: Tempo Brasileiro. - (1988). Zur Sache des Denkens. Tübingen: Max Niemeyer. - (1989). Überlieferte Sprache und technische Sprache. Attental: Erker. . (1994a). Beiträge zur Philosophie (Vom Ereignis) - Gesammtausgabe Band 65. Frankfurt am Main: Vittorio Klostermann. . (1994b). Die Armut. Heidegger Studien, Berlim, Vol. 10, p. 5-10. . (1995). Feldweg-Gespräche (1944/45) - Gesamtausgabe Band 77. . Frankfurt am Main: Vittorio Klostermann. 
- (1995). Nietəsche. Milano: Adelphi.

. (1996). Wegmarken. Frankfurt am Main: Vittorio Klostermann.

. (1997). Vorträge und Aufsätz̨e. Stuttgart: Neske.

. (1998a). Nietzsche - Ester Band. Stuttgart: Neske.

. (1998b). Nietzsche - Zweiter Band. Stuttgart: Neske.

- (1998c). Heráclito: a origem do pensamento ocidental: a doutrina heraclitica do

lógos. Rio de Janeiro: Relume Dumará.

. (1999). Conferências e Escritos Filosóficos. São Paulo: Nova Cultural.

. (2001). Ensaios e Conferências. Petrópolis: Vozes.

LEÃO, E. C. (1979). A viagem da educação. Revista Brasileira de Estudos

Pedagógicos (MEC), Brasília, vol. 63, n. 144, p. 11-16, maio-agosto de 1979.

• (2013). Filosofia Contemporânea. Teresópolis-RJ: Daimon. 